Koedoe 25: 117-119 (1982)

\title{
GROWTH OF A MALE CARACAL KITTEN FELIS CARACAL IN THE MOUNTAIN ZEBRA NATIONAL PARK
}

\section{J. H. GROBLER}

\author{
Department of Research and Information \\ Mountain Zebra National Park \\ Private Bag X66, \\ Cradock \\ 5880
}

Three caracal (lynx) Felis caracal kittens, two females and a male were received from the Fish River area some $50 \mathrm{~km}$ north of Cradock, Republic of South Africa, on the 20th March 1980. These were found at the base of a dense Rhus erosa bush on the side of a hill and estimated at 14 days old based on the findings of Cade (1968 Int. Zoo Yb. 45) and Kralik (1967 Int. Zoo Yb. 132).

The two females had a mass of $470 \mathrm{~g}$ and $540 \mathrm{~g}$ while the male weighed $460 \mathrm{~g}$. The eyes were open and had an opaque blue colour, the ears were erect and the coats a deep red brown colour. The teeth had not erupted through the gum and they could spit and growl. Once they were left alone they uttered a shrill bird-like call, not unlike a Cape Sparrow Passer melanurus. This call was used to communicate until the animal left at 10 months old.

The male was hand-reared on cow's milk and a variety of meat once this could be consumed. He was completely free ranging and remained very tame. His mass was determined on a weekly basis when possible and the body measurements were taken at the same time. Body measurements taken after 14 weeks old had a margin of error of $\pm 10 \mathrm{~mm}$. Shoulder height and heart girth were only measured at a later date. Mass was determined with the cat in a bag on a spring balance, and body measurements with a steel tape while being held.

Tooth eruption was difficult to determine because the animal disliked its mouth being opened. Hair colour changed with age and this was recorded.

Body measurements with increase in age are shown in Table 1. Increase in mass showed a close correlation with age and mass correlated well with other body parameters (Table 2).

The deciduous teeth appeared fully erupted at between four and six weeks old. At six weeks old the kitten was able to consume soft meat including a small bird. The permanent canines erupted at 25 weeks old and at one stage there were eight canines present. The deciduous canines only dropped out once the permanent canines were well erupted at between 26 and 27 weeks old.

The uniform brick red hair of the kitten was replaced by a paler reddish-brown colour by the age of 10 weeks old. At this age the eyes had become a yellow-lime 
Table 1

Body growth of a male caracal kitten in the Mountain Zebra National Park

\begin{tabular}{|c|c|c|c|c|c|c|c|}
\hline \multirow{2}{*}{ Age (wks) } & \multirow{2}{*}{ Mass $(\mathrm{kg})$} & \multicolumn{6}{|c|}{ BODY MEASUREMENTS IN MM } \\
\hline & & Tail & Ear & Hindfoot & Length & Shoulder & Girth \\
\hline 2 & 0,46 & 80 & 30 & 62 & 270 & - & - \\
\hline 3 & 0,52 & 90 & 30 & 70 & 330 & - & - \\
\hline 5 & 0,74 & 105 & 45 & 75 & 370 & - & - \\
\hline 6 & 0,91 & 105 & 48 & 83 & 410 & - & - \\
\hline 7 & 1,34 & 125 & 55 & 85 & 450 & - & - \\
\hline 8 & 1,53 & 140 & 60 & 100 & 480 & - & - \\
\hline 9 & 1,87 & 150 & 60 & 110 & 500 & 220 & - \\
\hline 10 & 2,21 & 165 & 65 & 125 & 580 & 230 & - \\
\hline 11 & 2,32 & 170 & 67 & 125 & 620 & 270 & - \\
\hline 12 & 2,83 & 180 & 67 & 130 & 530 & 300 & - \\
\hline 13 & 3,80 & 197 & 68 & 150 & 680 & 395 & - \\
\hline 14 & 4,00 & 202 & 70 & 160 & 700 & 305 & - \\
\hline 15 & 4,44 & 210 & 70 & 160 & 700 & 305 & - \\
\hline 16 & 4,80 & 210 & 70 & 160 & 740 & 310 & - \\
\hline 17 & 5,00 & 220 & 75 & 160 & 785 & 320 & - \\
\hline 18 & 5,40 & 240 & 80 & 170 & 780 & 330 & - \\
\hline 19 & 6,40 & 240 & 83 & 170 & 800 & 330 & - \\
\hline 20 & 6,60 & 250 & 83 & . 170 & 830 & 330 & - \\
\hline 21 & 6,80 & 250 & 84 & 170 & 830 & 340 & - \\
\hline 22 & 6,80 & 250 & 85 & 170 & 830 & 350 & - \\
\hline 23 & 7,20 & 250 & 85 & 170 & 875 & 350 & 340 \\
\hline 24 & 7,60 & 250 & 85 & 170 & 900 & 350 & 360 \\
\hline 25 & 8,00 & 250 & 85 & 170 & 900 & 370 & 400 \\
\hline 26 & 8,30 & 250 & 85 & 180 & 900 & 370 & 360 \\
\hline 27 & 8,80 & 260 & 85 & 190 & 920 & 370 & 360 \\
\hline 32 & 10,50 & 260 & 85 & 190 & 920 & 410 & 430 \\
\hline 35 & 11,20 & 285 & 85 & 200 & 1000 & 410 & 430 \\
\hline
\end{tabular}




\section{Table 2}

Correlation coefficients and linear regression formulae for various body parameters and age in a male caracal kitten

\begin{tabular}{lrlll}
\hline Mass & vs & Age (2 wks to 35 wks) & $\mathrm{r}=0,99$ & $\mathrm{y}=1,41 \mathrm{x}-0,92$ \\
\hline Mass & vs & Tail length $(2-20$ wks $)$ & $\mathrm{r}=0,97$ & $\mathrm{y}=0,04 \mathrm{x}-4,09$ \\
\hline Mass & vs & Ear length $(2-24$ wks $)$ & $\mathrm{r}=0,92$ & $\mathrm{y}=0,13 \mathrm{x}-4,76$ \\
\hline Mass & vs & Hindfoot length $(2-20$ wks $)$ & $\mathrm{r}=0,95$ & $\mathrm{y}=0,05 \mathrm{x}-3,60$ \\
\hline Mass & vs & Girth $(23-35$ wks $)$ & $\mathrm{r}=0,85$ & $\mathrm{y}=0,04 \mathrm{x}-4,69$ \\
\hline
\end{tabular}

green colour, and silver-white flecks of hair appeared on the rump. At 14 weeks old most of the body was covered in flecks of silvery-white hair.

The ears of the kitten were a uniform black on the dorsal surface. At 10 weeks old white hairs appeared amongst the black and by 21 weeks old there were prominent, almost pure white patches on the back of the ears. The ear tuft measured $20 \mathrm{~mm}$ at seven weeks old and $50 \mathrm{~mm}$ at 35 weeks old. 